\title{
Series Editor's Preface
}

'Victorian' is a term, at once indicative of a strongly determined concept and an often notoriously vague notion, emptied of all meaningful content by the many journalistic misconceptions that persist about the inhabitants and cultures of the British Isles and Victoria's Empire in the nineteenth century. As such, it has become a by-word for the assumption of various, often contradictory habits of thought, belief, behaviour and perceptions. Victorian studies and studies in nineteenth-century literature and culture have, from their institutional inception, questioned narrowness of presumption, pushed at the limits of the nominal definition, and have sought to question the very grounds on which the unreflective perception of the so-called Victorian has been built; and so they continue to do. Victorian and nineteenth-century studies of literature and culture maintain a breadth and diversity of interest, of focus and inquiry, in an interrogative and intellectually open-minded and challenging manner, which are equal to the exploration and inquisitiveness of its subjects. Many of the questions asked by scholars and researchers of the innumerable productions of nineteenth-century society actively put into suspension the clichés and stereotypes of 'Victorianism', whether the approach has been sustained by historical, scientific, philosophical, empirical, ideological or theoretical concerns; indeed, it would be incorrect to assume that each of these approaches to the idea of the Victorian has been, or has remained, in the main exclusive, sealed off from the interests and engagements of other approaches. A vital interdisciplinarity has been pursued and embraced, for the most part, even as there has been contest and debate amongst Victorianists, pursued with as much fervour as the affirmative exploration between different disciplines and differing epistemologies put to work in the service of reading the nineteenth century.

Edinburgh Critical Studies in Victorian Culture aims to take up both the debates and the inventive approaches and departures from 
convention that studies in the nineteenth century have witnessed for the last half-century at least. Aiming to maintain a 'Victorian' (in the most positive sense of that motif) spirit of enquiry, the series's purpose is to continue and augment the cross-fertilisation of interdisciplinary approaches, and to offer, in addition, a number of timely and untimely revisions of Victorian literature, culture, history and identity. At the same time, the series will ask questions concerning what has been missed or improperly received, misread, or not read at all, in order to present a multi-faceted and heterogeneous kaleidoscope of representations. Drawing on the most provocative, thoughtful and original research, the series will seek to prod at the notion of the 'Victorian', and in so doing, principally through theoretically and epistemologically sophisticated close readings of the historicity of literature and culture in the nineteenth century, to offer the reader provocative insights into a world that is at once overly familiar, and irreducibly different, other and strange. Working from original sources, primary documents and recent interdisciplinary theoretical models, Edinburgh Critical Studies in Victorian Culture seeks not simply to push at the boundaries of research in the nineteenth century, but also to inaugurate the persistent erasure and provisional, strategic redrawing of those borders.

Julian Wolfreys 